\title{
O Professor e a Avaliação em Sala de Aula
}

\author{
BERNARDETE A. GATTI \\ Doutora em Psicologia pela Universidade de Paris VII. Professora da Pontifícia \\ Universidade Católica de São Paulo - PUC-SP. Coordenadora do \\ Departamento de Pesquisas Educacionais da \\ Fundação Carlos Chagas, SP \\ gatti@fcc.org.br
}

\begin{abstract}
Resumo
O presente artigo discute a avaliação educacional como uma das formas de acompanhamento das atividades do aluno com o objetivo de promover a sua progressão. A autora procura suprir deficiências apresentadas nos cursos de formação de professores e mostra a importância da avaliação para fins de orientação, planejamento e replanejamento do ensino, ressaltando, por outro lado, a integração da avaliação no ensino e sua importância na apreciação das diversas aprendizagens e do autodesenvolvimento dos alunos. Aponta a responsabilidade dos professores como avaliadores, ressalta a avaliação em processo e, no final, faz novas considerações sobre a relação ensino/avaliação.

Palavras-chave: avaliação educacional, planejamento do ensino, orientação, avaliação em processo, ensino/avaliação.
\end{abstract}

\section{Resumen}

El presente trabajo discute la evaluación educacional como siendo una de las formas de acompañamiento del aluno para conseguir la promoción de su progreso. La autora intenta suplir las deficiencias presentadas en los cursos de formación de maestros y destaca la importancia de la evaluación con fines de orientación, planificación y replanteamiento de la enseñanza, explicitando, en contrapartida, la integración de la evaluación de la enseñanza y la importancia en la apreciación de los diversos aprendizados y del auto-desenvolvimiento de los alumnos. Muestra la responsabilidad de los profesores como evaluadores, resalta la evaluación del procedimiento $\mathrm{y}$, por último, hace nuevas consideraciones sobre la relación enseñanza/evaluación.

Palabras-clave: evaluación educacional, planificación de la enseñanza, orientación, evaluación en procedimiento, enseñanza/evaluación.

\begin{abstract}
This article discusses educational assessment as one of the follow-up forms of the student's activities as a way of promoting his/her progress. The author attempts to fill gaps detected in teacher training courses, shows the importance of assessment in the guidance, planning and re-planning of teaching activities, and highlights the integration of assessment into teaching and its relevance in appreciating students' various learning strategies and selfdevelopment. The article points out the teachers' responsibility as evaluators, emphasizes
\end{abstract}


assessment in process and, at the end, brings new light to the teaching/assessment relationship.

Key words: educational assessment, teaching planning, orientation, assessment in process, teaching/assessment. 


\section{INTRODUÇÃO}

Neste texto vamos tratar da avaliação educacional nas salas de aula. Estaremos, pois, enfocando o acompanhamento que o professor faz dos alunos em sua sala de aula ao longo do desenvolvimento de seu trabalho, com vistas à progressão dos alunos. A avaliação a ser desenvolvida pelos professores em classe tem merecido alguns estudos mas, em geral, pouca ou nenhuma orientação se dá nos cursos de formação de professores sobre este aspecto tão importante do desenvolvimento das atividades escolares. Esta avaliação tem por finalidade acompanhar os processos de aprendizagem escolar, compreender como eles estão se concretizando, oferecer informações relevantes para o próprio desenvolvimento do ensino na sala de aula em seu dia-a-dia, para o planejamento e replanejamento contínuo da atividade de professores e alunos, como para a aferição de graus.

Uma das características mais importantes desta avaliação é que o avaliador é, ao mesmo tempo, o responsável direto pelo processo que vai avaliar. É o próprio professor que trabalha com os alunos quem os avalia: não uma pessoa qualquer ou um técnico especializado. Isto implica que pensemos a avaliação em sala de aula como uma atividade contínua e integrada às atividades de ensino, algo que é decorrente destas atividades, inerente a elas e a seu serviço.

Para ter sentido, a avaliação em sala de aula deve ser bem fundamentada quanto a uma filosofia de ensino que o professor espose. A partir dessa premissa, o professor pode acumular dados sobre alguns tipos de atividades, provas, questões ou itens ao longo do seu trabalho, criando um acervo de referência para suas atividades de avaliação dentro de seu processo de ensino. É de todo importante que o professor possa criar, e verificar no uso, atividades diversas que ensejem avaliação de processos de aquisição de conhecimentos e desenvolvimento de atitudes, de formas de estudo e trabalho, individual ou coletivamente, para utilizar no decorrer de suas aulas. Todo este trabalho de acumulação e tratamento progressivo de dados sobre meios avaliativos para sala de aula exige dele um certo tempo de dedicação, que pode ser maximizado e socializado se a escola dispuser de um horário compartilhado de trabalho entre os docentes, no qual essa questão seja trabalhada.

Acumulando, analisando e refletindo sobre os meios avaliativos que venham a criar, os professores, bem como toda a equipe escolar, podem apurar e melhorar suas formas de avaliação e, portanto, tornarem-se mais justos na apreciação das diversas aprendizagens de seus alunos. 


\section{O PROFESSOR, O ALUNO E A AVALIAÇÃO}

Na literatura sobre a questão encontramos aspectos sugestivos que ajudam na reflexão sobre a condução de processos avaliativos em sala de aula. Nesses trabalhos verificam-se alguns elementos constantes, assim, por exemplo, em depoimentos de alunos encontra-se com freqüência que eles nem sempre percebem como o professor concebe a avaliação e qual seu papel na aula, para além de "dar uma nota". A maioria dos estudos (ver referências bibliográficas) mostra também que alto percentual dos alunos não consegue explicitar os critérios das "notas" que seus professores atribuem. Colocam, também, que questões com palavras vagas ou questões excessivamente detalhadas ou complexas levam à confusão e, como resultado, eles, alunos, não podem mostrar o que sabem sobre a matéria, mas sim, quanto eles são bons em tentar compreender - adivinhar - o que o professor quer. Isto vale tanto para questões abertas, quanto para itens fechados, nos quais têm que entender o que é pedido pelo professor na formulação do item e também o que cada alternativa quer dizer. É freqüente, nestes estudos, a observação de que o professor sempre pode "pegar" os alunos, mesmo com testes, basta que faça questões capciosas ou ambíguas ou com alternativas confusas.

Dados obtidos com professores mostram que não há uma maneira universal, única ou melhor para avaliar os alunos em classe. As provas são vistas pelos docentes como um instrumento que "mede" a aprendizagem e são praticamente o único tipo de instrumento de que se valem para a avaliação. Analisando dados de pesquisas com professores nota-se que varia o grau em que estes usam as provas como meio de ensino e também de aprendizagem, como forma de obter informações relevantes sobre o processo de desenvolvimento escolar dos alunos e sobre seu próprio processo de ensino. Na verdade, poucos têm em mente estas questões, ficando a avaliação restrita apenas a um processo de verificação que se baseia em concepções nem sempre claras sobre o que julga que os alunos devam ter retido, sintetizado ou inferido dos conteúdos tratados. Encontrase um certo percentual de professores que pensam que as provas em si são instrumento de aprendizagem. Selecionamos na literatura alguns depoimentos interessantes, embora estes não representem a tônica mais comum nas concepções sobre os processos de avaliação em sala de aula: "Penso que os estudantes podem aprender enquanto estão fazendo uma prova, desde que se dê a eles questões sobre as quais tenham que pensar. Sinto também que a aprendizagem é maior quando feita durante as provas" (Professor de Estudos Sociais). "Uso minhas provas como um meio de ensino. Tento elaborar questões que levem as crianças a aprender alguma coisa" (Professor de História). "As provas, em geral, são usadas apenas para classificar os alunos. As crianças, é 
claro, pensam isto também. Quando você faz uma prova, a única razão pela qual você a faz é para obter algum grau; não como um processo de aprendizagem. Mas ela pode ser usada como um processo de aprendizagem e eu tento fazer isto" (Professor de Inglês). Nestes depoimentos verifica-se entre esses docentes uma nova cultura quanto ao papel dos processos avaliativos em sala de aula, o que sinaliza que estão se processando mudanças nas concepções dominantes sobre esse processo na escola. Estas posturas também se associam a uma nova maneira de conceber as finalidades e o papel da educação escolar.

Observa-se também que a atribuição de notas ou gradações a um grupo de alunos é algo bastante pessoal entre os professores. Mesmo quando recebe instruções estritas quanto a como fazê-lo, introduzem em algum ponto variações que lhes permitem dar seu cunho pessoal à avaliação. Há sempre um certo grau de subjetividade que atua no processo e isto nem sempre é objeto de reflexão por parte do professor. Há uma consideração individualizada por mais que tente ser, ou queira ser objetivo (por exemplo, para com os alunos que ficam nas proximidades dos limites de aprovação quando procedem a ajustamentos e aproximações). Extraímos, como ilustração, alguns depoimentos de vários trabalhos: "Tiro a média de trabalhos de casa, problemas e provas. Verifico se esta média representa realmente o que o estudante parece saber. Eu ajusto, se julgar necessário" (Professor de Matemática). "Vejo qual o número máximo possível de pontos a serem obtidos, depois determino a posição do estudante numa base de qual a porcentagem de pontos que obteve. Considero notas de provas, chamadas orais, trabalhos escritos, participação em classe, conduta e quanto um aluno melhorou" (Professor de Ciências). "Atribuo notas na base de uma porcentagem de pontos possiveis. Atribuo pontos a provas, problemas e trabalhos de casa. Os alunos que ficam no limite de aprovação são considerados individualmente quanto à sua participação em classe e atitude" (Professor de Matemática). "Transfiro os pontos em números para letras. Somo os pontos e divido pelo número de graus e então determino o grau médio que atribuirei. Aqui minha avaliação subjetiva interfere" (Professor de Português).

Fica evidente que uma grande variedade de formas de avaliação é usada, em que pese a aparente uniformidade nas atribuições de notas. Evidencia-se nas pesquisas, pelas falas dos docentes, que, para cada um deles, seus próprios procedimentos são considerados, em geral, os melhores e mais justos para determinar as notas dos alunos. Mas as aproximações a que procedem, as considerações que usam para alterar padrões fixos, etc. precisariam merecer uma análise constante por parte dos professores. Não se trata de eliminar esse grau de julgamento, mas tornálo mais explícito e analisável constantemente. 
A diversidade de opiniões sobre as avaliações que se processam em sala de aula, tanto entre os professores, como entre os alunos, e ainda entre alunos e professores, fica patente. O único ponto comum é a visão de que a avaliação dos alunos é uma parte esperada e essencial do processo de educação. Como esta avaliação deve ser realizada é uma questão aberta para debate. Debate que pode ser realizado em sala de aula entre professores e alunos na busca de maior transparência desse processo e de melhor utilização dos vários meios possíveis de serem utilizados ou criados para alimentar relevantemente os processos de ensino do professor e os de aprendizagem dos alunos.

Em alguns dos estudos analisados observa-se que a participação pessoal do professor, com seus juízos de valor, ao avaliar o aluno, é intrínseco a esse processo, mesmo quando é treinado no uso de procedimentos mais sistematizados. Isto traz ao primeiro plano de considerações a responsabilidade de cada professor como avaliador perante seus próprios alunos e a necessidade de que reflita sobre suas concepções quanto ao papel da avaliação em seu trabalho com os alunos. Traz, também, à tona a necessidade de que cada professor procure aprimorar seus meios de avaliação, tentando familiarizar-se com o uso de meios variados de tal modo que possa criar e ajustar procedimentos avaliativos que sejam os mais adequados aos seus objetivos de ensino, à linguagem dos conteúdos tratados e à linguagem de seus alunos, e que possam contribuir não só para situar o grupo de alunos e cada aluno face à sua aprendizagem, mas também para estimular esta aprendizagem. Que a avaliação não seja apenas finalista mas, sim, incluída no processo de ensino e aprendizagem como meio para o autodesenvolvimento, tanto dos alunos em suas aprendizagens, quanto dos professores, como profissionais, em face das suas formas de ensinar.

Assim, torna-se muito importante a atitude do professor diante do processo de avaliação. Como ele a concebe? Como a situa em seu trabalho de ensino? Como a realiza? Como a utiliza?

\section{A RESPONSABILIDADE DOS PROFESSORES}

Vamos apontar alguns aspectos relativos a processos de avaliação em sala de aula que, quando levados em conta, cremos, podem aprimorar as formas de acompanhar e avaliar as aprendizagens dos alunos de modo mais construtivo, bem como melhorar as situações em que se fazem as provas, de tal forma que estas possam ser realizadas em condições que favoreçam ao aluno exprimir o que realmente sabe. 
Inicialmente devemos lembrar que, embora comentando aspectos relativos às provas que se utilizam em sala de aula, quer do ponto de vista de sua elaboração, quer das condições de sua aplicação, estas não devem ser os únicos instrumentos de avaliação que os professores venham a utilizar. É que, em geral, são os instrumentos que têm maior peso na avaliação e os mais comumente usados.

A importância atribuída pelos professores às provas na determinação da avaliação dos alunos é muito conhecida por estes. Em geral, uma grande ansiedade é desenvolvida na preparação para uma prova, na sua realização e na discussão dos resultados em sala de aula. Tudo isto interfere na realização do aluno e na sua aprendizagem. Muitos professores orgulham-se da dificuldade de suas provas e não sentem que deram uma boa prova se muitos alunos tiraram nota alta. No outro extremo, temos os professores que tornam suas provas tão simples que não chegam a suscitar no aluno nenhum comportamento de empenho pessoal para realizá-las. No primeiro caso, desenvolve-se nos alunos um grau de ansiedade, de frustração ou de sentimento de injustiça que interfere negativamente em seu processo de aprendizagem. No segundo, criam-se condições de indolência e nenhum empenho para aprender, muitas vezes associadas a sentimentos relativos ao desinteresse do professor pelos alunos e pelo seu trabalho.

Sentimentos negativos em relação às provas vão sendo desenvolvidos ao longo dos anos de escolarização e, indubitavelmente, se se quiser mudá-los leva-se algum tempo. Porém algumas medidas podem ser tomadas para o desenvolvimento de atitudes mais positivas em relação às provas. Podemos destacar alguns aspectos relativos a esta questão para reflexão e discussão.

Primeiro, cuidar do que parece óbvio, mas nem sempre é cuidado: preparar bem as provas e os alunos para as realizar. Para que estas se tornem situações de aprendizagem, o professor deve dispender algum tempo na identificação de quais aspectos de ensino de sua disciplina foram realmente trabalhados em classe no período a ser avaliado, quais dentre estes serão incluídos na prova e por quê. Depois de determinar o que será avaliado, é importante discutir com os alunos as questões trabalhadas em sala de aula, sinteticamente, conversando sobre compreensões e incompreensões, procurando explicitar, recordando os conteúdos já trabalhados de modo simples, claro e direto. Os alunos, tomando essa síntese e revisão como orientação para seus estudos, poderão então engajar-se em uma experiência de aprendizagem desafiadora e com significado. Se o professor vai utilizar um tipo de prova com que os alunos não estão familiarizados, deve trabalhar com eles em exemplos dos tipos de questões que vai usar (evidentemente com outro conteúdo). Com isto, a 
prova do aluno dará ao professor uma idéia de quanto ele sabe sobre o conteúdo da questão e não quanto ele sabe lidar com um certo tipo de questão ou não. Isto porque, muitas vezes, o aluno não apresenta um bom desempenho na prova, não porque não domine nada do conteúdo da matéria, mas porque não entendeu como lidar com o tipo de questão proposta pelo professor.

Segundo, dar provas com certa freqüência. Um número maior de provas permite uma diminuição da pressão sobre os alunos quanto ao seu desempenho, dado que este é avaliado em um maior número de situações; também oferecem informações mais numerosas e próximas, no tempo, sobre o desenvolvimento do aluno nas matérias, facilitando seu acompanhamento e sua programação pessoal de estudos, bem como de todo o grupo-classe. Observa-se uma melhoria no clima de aprendizagem da classe quando os alunos percebem que as provas mais freqüentes são dadas para acompanhar seu progresso na aprendizagem em relação aos trabalhos desenvolvidos em sala de aula e para estimulá-los em suas aprendizagens. $\mathrm{O}$ professor pode mostrar aos alunos como as provas podem ser usadas não só para identificar o que foi aprendido e de que modo ocorreu a aprendizagem, como também para detectar aquelas áreas em que algum ensino adicional será necessário para melhor compreensão da matéria. Com esta atmosfera, os alunos, usualmente, sentem menos pressão e maior motivação para aprender.

Terceiro, usar a prova corrigida como meio de ensino. É produtivo oferecer aos alunos, o mais cedo possível, os resultados de suas provas, com comentários, dando oportunidade para uma discussão detalhada sobre por que a questão correta está correta, quais os principais problemas de compreensão sobre a matéria foram encontrados entre os alunos, qual o raciocínio necessário a cada questão. Com isto, suprem-se dúvidas e lacunas de aprendizagens anteriores e prepara-se o terreno para as que virão. Sem isto, o professor estará "ensinando no escuro", sem saber em que alicerce está levantando a parede. Discussões coletivas sobre as questões da prova, sem personalizar resultados, também são um meio de alavancar aprendizagens em relação a pontos valiosos para o acervo de conhecimento dos alunos.

O professor pode, ainda, ajudar os alunos a superarem sua tensão emocional durante as provas, sugerindo alguns meios, como: tomar conhecimento da prova toda para ter uma idéia geral de seu conteúdo, da extensão e tipo de questões, a fim de programar seu tempo e as respostas que dará em primeiro lugar, etc.; responder às questões que sabe bem e deixar as mais problemáticas para tratar com mais vagar depois; não se preocupar com a resposta perfeita, ideal, mas com o que pode fazer e mostrar, etc. 
Outro ponto que parece importante considerar é o professor procurar compreender por que os alunos colam ou tentam colar em uma prova. Alguns, tratam o problema da cola dramaticamente (tirando a prova, dando zero, etc.), outros, virtualmente, a ignoram. Mas, na verdade, a maioria dos professores se sente perturbada quando suspeita da cola, e a penalidade para quem é surpreendido colando é, em geral, severa. A cola não é nova. A maioria dos alunos quer obter os graus necessários para aprovação ou são pressionados a obtê-los pela família ou outros grupos de influência. Outros se sentem inadequados ou inadaptados aos padrões de funcionamento acadêmico da escola. Como resultado, recorrem à cola. Qualquer que seja o caso, o professor deve procurar compreender por que determinados alunos recorrem a esta prática e tentar desenvolver para cada caso algum esforço para minimizar o problema, lidando com os casos específicos a fim de que este comportamento desapareça. Não há regras para isto. $O$ professor deve encontrar os caminhos, sendo sempre interessante uma conversa para desvelar os motivos do aluno. Por outro lado, pode tentar, em classe, diminuir as oportunidades de cola, organizando várias formas equivalentes de provas, por exemplo, ou organizando questões que merecem consultas e respostas mais individualizadas, fazendo algumas avaliações por meio de atividades em grupo, etc.

Mas parece que a melhor maneira de diminuir as pressões que levam à cola é a preparação adequada do aluno para enfrentar a situação de prova, além das atitudes do próprio professor em relação ao papel desse instrumento dentro de sua filosofia de ensino, como já destacamos. Ainda, o professor pode dar aos alunos informações sobre outras oportunidades de trabalhos, atividades diversificadas ou provas extras, caso não tenham bom desempenho nas provas regulares. Por outro lado, se o professor se preocupa em mostrar para os alunos (e se ele assim acredita e faz) que ambos estão empenhados no mesmo processo e que o problema de aprendizagem de um é o problema de ensino do outro e que os graus são meios de ambos "regularem seus motores", muito da pressão que as provas provocam será diminuída.

É preciso, ainda, considerar que a preparação de uma prova, seja de que tipo for, deve ser feita tendo em conta alguns cuidados básicos para que se possa garantir que ela vai ser um instrumento que reflita o melhor possível o que o aluno sabe. Em geral os professores propõem muitas questões sobre as avaliações que devem fazer: como organizar uma prova que dê um bom referente sobre a realização de cada aluno? Qual a confiança que se pode ter nos resultados de uma avaliação? Que elementos podem interferir nas notas dos alunos? 
Apesar dos diferentes tipos de questão que um professor pode usar na elaboração de uma prova há algumas características importantes que qualquer prova deve ter. Por exemplo, deve estar referida ao que realmente foi trabalhado em sala de aula e deve cobrir o material que o professor trabalhou com os alunos e as formas pelas quais trabalhou. Ou seja, a prova deve cobrir a maior parte possível do conteúdo do ensino desenvolvido e ser equilibrada com relação à ênfase que o professor atribuiu às várias partes do conteúdo e às formas pelas quais abordou esse conteúdo com os alunos. Então, uma vez que diferentes tipos de aprendizagens estão envolvidos no ensino, diferentes tarefas de prova são necessárias para verificar o quê e como os alunos apreenderam os significados dos conteúdos abordados. A prova precisa ser construída de tal forma que as várias possibilidades de aprendizagens possam ser acionadas revelando as diferentes maneiras pelas quais conteúdos podem ser aprendidos.

Alguns fatores podem ser apontados como interferindo na qualidade de uma prova e, portanto, merecendo atenção por parte do professor:

- a qualidade das questões ou itens - estes devem ser formulados de tal modo que os alunos entendam exatamente o que é pedido, ou seja, não devem se prestar a interpretações dúbias (cuidados com a linguagem utilizada);

- a extensão da prova deve ser cuidada - em geral, quanto maior o número de questões maior as possibilidades para os alunos expressarem seus conhecimentos, dado que, com um maior número de questões, pode ser realmente abrangida a maior parte dos conteúdos e objetivos visados com esses conteúdos e os variados tipos de aprendizagem possíveis. Porém, a extensão deve ser calibrada pela avaliação do cansaço que a prova pode provocar e do tempo disponível para a realização da mesma;

- o nível de dificuldade da prova - se esta é muito fácil todos os alunos responderão a tudo ou a grande parte; se ela é muito difícil, as notas tenderão todas a ser muito baixas. Dizemos, em um caso e noutro, que a prova não discriminou os conhecimentos diferenciados dos alunos; a prova deve ser equilibrada em seu grau de dificuldade;

- a forma de atribuir os pontos às questões - é preciso que a atribuição de pontos seja consistente, equivalente de aluno para aluno. Um padrão de correção deve ser estabelecido cuidadosamente antes da aplicação de qualquer prova e discutido após com os alunos; 
- o ambiente onde a prova é realizada - a classe deve estar livre o mais possível de barulhos, ruídos incômodos ou movimentos que possam perturbar os alunos a ponto de atrapalhar sua concentração ou dedicação à tarefa;

- o estado emocional dos alunos - a ansiedade, a angústia ou a excitação que muitos alunos experimentam em situação de prova tendem a perturbar sua realização; os professores devem organizar suas provas de tal forma que consigam diminuir estas influências emocionais ao mínimo, como já apontamos em outra parte deste texto.

Outros fatores podem, ainda, influenciar a realização de uma prova e o professor deve estar atento ainda aos seguintes pontos:

- dar instruções bem claras quanto à prova, quanto ao tipo de questões envolvidas, como organizar ou dar respostas, enfim, tudo o que diz respeito à forma da prova deve estar bem claro para os alunos;

- caso as questões forem impressas, devem estar situadas na página de modo que sejam facilmente lidas; cada questão deve estar inteiramente contida em uma página;

- todas as correções nas questões impressas devem ser feitas antes de se dar ao aluno o papel de prova;

- a prova deve conter em primeiro lugar as questões mais simples de serem respondidas, o que deve encorajar o aluno a prosseguir e diminuir sua tensão.

Concluindo, uma prova de classe será tanto melhor quanto for o mais possível válida e coerente dentro das condições do quotidiano da escola. Uma prova válida cobre não só o conteúdo de uma seqüência de aprendizagens, como também os variados tipos de aprendizagens que estão implícitas nas atividades de ensino tal como desenvolvidas em sala. Uma prova coerente dá resultados nos quais o professor pode confiar.

\section{AVALIAÇÃO EM PROCESSO}

Angelo e Cross (1993) consideram que o professor precisa ter uma série de meios de avaliação, não muito longos e que possam ser usados de modo mais continuado no correr das aulas, criados e aplicados pelos próprios professores, e cuja finalidade seria fornecer ao professor uma informação freqüente e contínua sobre o progresso acadêmico de seus 
alunos. O fluxo contínuo de informações precisas, que avaliações rápidas em classe fornecem sobre o aprendizado dos alunos, permite aos professores avaliar sua própria forma de ensino e redirecionar seus objetivos e formas de apresentar os conteúdos, adequando-os para que os alunos compreendam e assimilem as informações relevantes no nível necessário. Afinal, este é o papel essencial do professor, uma vez que a função de ser apenas um apresentador de informações um bom livro pode cumprir talvez melhor este papel. Essas avaliações continuadas têm pois o objetivo de ajudar a direcionar e redirecionar o trabalho do professor em seu dia-a-dia, podendo, pela atuação deste, contribuir também para que os alunos compreendam e superem suas dificuldades ou ampliem seus conhecimentos.

Os autores referidos caracterizam esse tipo de avaliação em aula como sendo: 1) centrada em quem aprende - com o foco na observação dos alunos; 2) mutuamente benéfica - capaz de ajudar os alunos a aprenderem a se avaliar, bem como ajudar os professores a avaliar tanto a si mesmos como aos alunos; 3) formativa - orientada no sentido não de dar notas nem classificar alunos, mas no sentido de determinar quanto eles aprenderam, quais dificuldades e facilidades têm; 4) de contexto específico - adaptável a variáveis da classe, tais como o estilo e a experiência do professor, às necessidades de aprendizagem dos alunos e às características de um particular conteúdo; 5) em constante andamento - planejada para criar um fluxo de informação constante, como um círculo, no qual os estudantes informam aos professores que por sua vez informam aos alunos; e 6) com raízes em boas práticas de ensino - aquelas que se reforçam ou refazem com as avaliações procedidas.

Em seu texto, Angelo e Cross descrevem muitas maneiras diferentes de processar avaliações rápidas em classe, no correr das aulas, as quais os professores podem adaptar às suas necessidades individuais e, a partir delas, criar outras. Segundo os autores, foram elaboradas para servir a uma grande variedade de tamanhos de classe, contextos, disciplinas e objetivos, e são breves, com a intenção de serem aplicadas no período de aula, integradamente às atividades de ensino, e têm o objetivo de avaliar o que os alunos apreenderam de partes específicas da aula ou avaliar o desenvolvimento de uma determinada habilidade que está sendo trabalhada com o grupo classe.

A técnica de avaliação em classe utilizada de maneira mais geral é o chamado "Trabalho de Minuto". Angelo e Cross explicam: "Para empregar o Trabalho de Minuto, o professor interrompe a aula uns dois ou três minutos mais cedo e pede aos alunos que respondam brevemente a alguma variação das duas perguntas seguintes: 'Qual foi a coisa mais importante que você aprendeu nesta aula?' e 'Qual foi a questão importante que ficou 
sem resposta?' Os estudantes escrevem suas respostas e as entregam" (p.148).

A vantagem do Trabalho de Minuto, como a de muitos outros meios avaliativos que esses autores descrevem, é que, com um pequeno investimento de tempo, os professores conseguem perceber como os seus alunos estão compreendendo partes específicas das aulas e podem então alterar sua forma de ensinar de acordo com a informação coletada, se for o caso. Essa avaliação continuada, integrada às atividades de ensino em sala de aula, voltada para a verificação dos avanços/dificuldades dos estudantes, é a própria essência de um bom ensino e da melhoria das aprendizagens.

Evidentemente, os professores não devem usar mecanicamente as sugestões citadas por Angelo e Cross, ou qualquer outro autor. As descrições dessas maneiras de avaliar servem de referência para novas criações, adaptações, modificações, etc. A chave da contribuição dessas pequenas verificações avaliativas está em serem personalizadas pelo professor e ajustadas ao grupo-classe.

Como a finalidade destas técnicas de avaliação em classe é avaliar como um grupo de alunos está aprendendo, as questões de mensuração padronizada não têm grande importância. Os professores podem apreender o que querem saber sem se preocupar com a comparação de suas verificações com as de outros grupos de estudantes, nem com outros semelhantes. Naturalmente, como acontece com outros procedimentos avaliativos, as chances de que os professores aperfeiçoem suas avaliações escolares aumentam grandemente quando elas são bem pensadas, bem planejadas e quando têm oportunidade de discutir os processos avaliativos empregados e seus resultados com colegas professores e outros profissionais da educação. Por outro lado, como esta forma de avaliação tem um foco bastante restrito, os professores não podem usá-la para generalizar e, por meio delas, é difícil que se consiga avaliar o "quadro maior" ou o nível geral do aprendizado do aluno.

\section{ENSINO E AVALIAÇÃO: CONSIDERAÇÕES GERAIS}

Há questões de base que devem estar presentes quando se pensa, se planeja e se faz avaliação de alunos em seu processo de aprendizagem. Estas questões dizem respeito à construção e vivência de uma filosofia que fundamente o trabalho educacional que sustente uma concepção de currículo; portanto, que haja a superação da concepção fragmentada de ensino que prevalece hoje em nossas escolas: em geral, não há uma filosofia de trabalho de formação que seja o eixo articulador de todas as 
atividades didáticas na escola e que dê sentido e defina o papel que cada atividade tem na trajetória a ser percorrida por professores e alunos nas salas de aula ou na escola. Havendo um eixo norteador consensuado e conhecido, partilhado, assumido e renovado, com compromisso, por todos os envolvidos na formação das crianças e jovens, as articulações das aprendizagens serão amplamente favorecidas e a avaliação tomará sentido a partir desse eixo. Ou seja, um bom ensino só se processa em um ambiente em que a integração curricular é vivenciada coletivamente e um processo de avaliação de alunos adquire seu pleno sentido no âmbito desta totalidade e na especificidade do papel que cada atividade ou disciplina tem no concerto do conjunto a que pertence.

Não há como separar avaliação de ensino, não há como pensar avaliação de alunos sem que se tenha claro o papel da educação na vida das pessoas. A estrutura e a dinâmica das escolas, com vistas à formação de pessoas, de cidadãos, deveriam mostrar-se como uma orquestra, a fim de apresentar no final do concerto, pelo menos até certo ponto, uma obra harmônica e com sentido. Cada instrumento com seu papel, cada disciplina com seus objetivos integrados e harmonizados no conjunto, em função de metas mais amplas a atingir. Em um contexto assim colocado, a avaliação dos alunos é atividade que adquire um sentido específico, orientada pelo papel da escola. Ao professor devem ficar claros os aspectos mais importantes a avaliar, não na direção apenas do tópico específico de que trata, mas de seu significado na formação da criança ou jovem, formação esta mais amplamente compreendida.

É preciso ter presente, também, que medir é diferente de avaliar. Ao medirmos algum fenômeno por intermédio de uma escala, de provas, de testes, de instrumentos calibrados ou por uma classificação ou categorização, apenas estamos levantando dados sobre a grandeza do fenômeno. Temos um número, a freqüência em uma categoria, etc. Sabemos o sentido destas grandezas se tivermos algum critério de comparação: grande, pequeno, muito, pouco, etc. Mas, a partir das medidas, para termos uma avaliação é preciso que se construa o significado destas grandezas em relação ao que está sendo analisado quando considerado como um todo, em suas relações com outros fenômenos, suas características historicamente consideradas, o contexto de sua manifestação, dentro dos objetivos e metas definidos para o processo em avaliação, considerando os valores sociais envolvidos. Como dizem Amorim e Souza (1994) a "avaliação não é algo que se dê de modo dissociado do objeto ao qual se dirige e não se concretiza independentemente dos valores dos sujeitos em interação. Assim, os princípios norteadores de uma proposta avaliativa $e$ de seu próprio processo de construção representam uma explicitação do posicionamento de sujeitos frente a um determinado segmento da realidade, 
sujeitos esses que ocupam diferentes lugares sociais, o que leva ao afloramento de divergentes e conflitantes ênfases na avaliação." (p.125)

Em seu sentido mais amplo, então, uma avaliação é um julgamento de valor. No caso de nosso interesse, a avaliação em sala de aula é um julgamento para se saber até que ponto alunos atingem objetivos valiosos em aprendizagens diversificadas em relação a um certo conteúdo considerado necessário ao seu desenvolvimento pessoal; como o fazem e quais atitudes e valores revelam que sejam pertinentes ao seu domínio vivencial. Não basta, pois, apenas medir ou levantar dados, por testes, provas clássicas ou questionários; estes instrumentos dão base para se começar um processo avaliativo mas não são suficientes; é preciso inferir, comparar, analisar conseqüências, examinar o contexto, estabelecer valores, aquilatar atitudes, formas de comunicação, fazer a autocrítica de valores pessoais, etc. e, para tanto, é necessário que se tenha algum suporte referencial em concepções educacionais, fundamentado em reflexões e consensos, trabalhado antes, durante e depois do processo avaliativo. Um trabalho integrado de professores e alunos.

Ao avaliar seus alunos os professores estão avaliando a si mesmos, embora a maioria não tenha consciência disto ou admita isto. Ensino e aprendizagem são indissociáveis e a avaliação é intrínseca a esse processo. A avaliação daqueles a quem se propôs ensinar algo também traz informações sobre como se procurou ensinar esse "algo". Alguém atuou neste "como": o professor. Então, o melhor indicador da realização de uma atividades de ensino é o nível em que nela, pela ação docente, se promove o crescimento geral dos alunos: cognitivo, afetivo, motor, atitudinal, comunicacional, valorativo, etc.

Avaliar o aluno tem um referente direto: o ensino tal como desenvolvido pelo seu professor na particular disciplina ou atividade, em uma dada escola. Pensar um processo de avaliação de alunos sem que este se integre no planejamento e desenvolvimento das atividades de ensino do professor no contexto da escola, gera algumas avaliações que conhecemos sobejamente: muitas vezes tecnicamente bem feitas, mas vazias de sentido ou tecnicamente péssimas e ainda mais vazias de sentido.

O exercício da docência com propósitos claros e consensuais alimenta um processo de avaliação mais consistente e mais integrado na direção de uma perspectiva formativa, voltada para o desenvolvimento dos alunos e não para cumprir uma formalidade burocrática - passa/não passa - ou mesmo para satisfazer o exercício de autoritarismos ou autoafirmações pessoais. Nesta perspectiva, a avaliação do aluno é continuada, variada, com instrumentos e elementos diversificados, criativos e utilizada no próprio processo de ensino, como parte deste, na direção de 
aprendizagens cognitivo-sociais valiosas para os participantes desse processo.

\section{REFERÊNCIAS BIBLIOGRÁFICAS}

ALVES, I. M. de A. A avaliação da aprendizagem em duas escolas públicas de Salvador: tendências e perspectivas. Dissertação (Mestrado em Educação), Universidade Federal da Bahia, 1997.

AMORIM, A.; SOUZA, S. M. Z. L. Avaliação institucional da universidade brasileira, Estudos em Avaliação Educacional, FCC, São Paulo, n.10, 1994.

ANGELO, T. A.; CROSS, K. P. Classroom assessment techniques: a handbook for college teachers. (2nd. ed.). San Francisco, Jossey Bass, 1993.

BATSCHAVER, A. M. de B. Do sujeito avaliador na prática da avaliação escolar: a identidade que fala e sente. Dissertação (Mestrado em Educação), Pontifícia Universidade Católica de São Paulo - Supervisão e Currículo, 1993.

BERTAGNA, R. H. Avaliação da aprendizagem escolar: a visão de alunos de quarta e quinta séries do primeiro grau. Dissertação (Mestrado em Educação), Universidade Estadual de Campinas, 1997.

BROWN, A. J. Appraisal Procedures in the Secondary Schools. Practice-Hall, N. Jersey, 1970.

CAETANO, J. J. A subjetividade no ensino de matemática: investigando as correções de provas escritas de matemática no ensino médio. Dissertação (Mestrado em Educação), Universidade Federal do Paraná, 1998.

CAMARGO, A. L. C. O discurso sobre a avaliação escolar do ponto de vista do aluno. Tese (Doutorado em Educação), Universidade Estadual de Campinas, 1996.

DALBEN, A. I. L. F. Avaliação escolar: um processo de reflexão da prática docente e da formação do professor no trabalho. Tese (Doutorado em Educação), Universidade Federal de Minas Gerais, 1998.

DARSIE, M. M. P. Avaliação e aprendizagem. Cadernos de Pesquisa, São Paulo, n. 99, p.47-59, nov. 1996. 
DART, R. T. Comportamentos indicativos e fatores responsáveis pela ansiedade do aluno em situações de avaliação. Dissertação (Mestrado em Educação), Universidade Federal do Rio de Janeiro, 1984.

GAMA, Z. Z. A avaliação na escola de segundo grau: primeira série do segundo Grau. Dissertação (Mestrado em Educação), Pontifícia Universidade Católica do Rio de Janeiro, 1993.

GOMES, J. A. O processo de avaliação de desempenho escolar em ciências no primeiro grau (quinta a oitava séries): uma análise sobre a percepção dos docentes e alunos. Dissertação (Mestrado em Educação), Pontifícia Universidade Católica do Rio Grande do Sul, 1991.

GOTTMAN, J. M.; CLASEN, R. E. Evaluation in Education: a practitioners guide, Peacock, 1972.

GUILHERME, C. C. F. Avaliação no Ciclo Básico: concepções, práticas e dificuldades. Dissertação (Mestrado em Educação), Universidade Federal de São Carlos, 1998.

LOURENÇO FILHO et al. Três ensaios sobre avaliação educacional. CETPP-FGV, 1968.

PAREDES, M. A. T. Avaliação formativa: uma experiência com alunos do secundário. Dissertação (Mestrado em Psicologia da Educação), Pontifícia Universidade Católica de São Paulo, 1984.

POPHAM, W. J. Como avaliar o ensino. Ed. Globo, Porto Alegre, 1976.

RAPHAEL, H. S. A avaliação em salas de aulas públicas: tentando sua compreensão. Dissertação (Mestrado em Educação), Universidade Estadual Paulista - Campus Marília, 1993.

RESSLER, M. S. A avaliação e o cotidiano escolar: do discurso à prática de professores de séries iniciais. Dissertação (Mestrado em Educação), Pontifícia Universidade Católica do Rio Grande do Sul, 1996.

SAMESHIMA, D. C. T. Avaliação da aprendizagem matemática da perspectiva do professor. Dissertação (Mestrado em Educação), Universidade Estadual Paulista - Campus Rio Claro, 1996. 
SANTOS, M. A. dos. Desvelando o jogo da avaliação entre professor e o aluno. Dissertação (Mestrado em Educação), Pontifícia Universidade Católica de São Paulo - Psicologia da Educação, 1994.

SILVA, C. A. N. Avaliação: uma faca de dois gumes - um estudo sobre a prática avaliativa nas escolas. Dissertação (Mestrado em Educação), Universidade Metodista de Piracicaba, 1998.

SOUZA, N. A. de. A concepção de avaliação da aprendizagem do professor alfabetizador do ciclo básico paranaense. Dissertação (Mestrado em Educação), Universidade Estadual Paulista - Campus Marília, 1995.

TURINI, L. D. A. A avaliação no contexto da ação pedagógica do professor de História. Dissertação (Mestrado em Educação), Universidade Federal de Uberlândia, 1995.

TURRA, C. M. G. et al. Planejamento de Ensino e Avaliação. PUC-Meridional, Porto Alegre, 1975.

VASCONCELOS, C. dos S. Processo de mudança da avaliação da aprendizagem: o papel do professor, representações e práticas. Tese (Doutorado em Educação), Universidade de São Paulo, 1998.

ZAMBELLI, P. C. Avaliação: um permanente desafio. Tecnologia Educacional, 25, 136-137, Rio de Janeiro, 1997, p.57-60. 